\title{
A Possible Role for Chemerin; a Novel Adipokine in the Haemostatic and Atherogenic Disorders Related to Obesity in White Albino Rats
}

\author{
Enas N. Morgan ${ }^{\mathrm{a}, \mathrm{b}}$ and Husam M. Edrees $\mathrm{e}^{\mathrm{a}, *}$ \\ ${ }^{a}$ Department of Physiology, Faculty of Medicine, Zagazig University, Zagazig, Egypt \\ ${ }^{b}$ College of Medical Rehabilitation, Qassim University, Saudi Arabia
}

\begin{abstract}
A strong link between obesity, hypercoagulability and thrombogenesis, had been recognized. Chemerin is a novel adipokine that has been activated by the coagulation process and suggested to play an important role in the pathogenesis of metabolic syndrome. We aimed to identify the possible relationship between chemerin levels and haemostatic changes in the high fat diet (HFD) fed rats. A total number of 20 adult male albino rats were divided into two groups of 10 rats each. Group I, rats served as controls; Group II: rats received high fat diet (58\% fat) for 8 weeks. In both groups, serum levels of glucose, insulin, chemerin, total cholesterol (TC), triglycerides (TG), HDL, LDL were measured. As well as the bleeding time (BT), whole blood clotting time (WBCT), Prothrombin time (PT), Activated partial thromboplastin time (aPTT), fibrinogen level and C- reactive protein (CRP) were measured. Moreover HOMA-IR was calculated for both groups. The results of the current study revealed that chemerine level increased significantly in the HFD- fed rats $(p<0.001)$. In addition, a significant positive correlation was detected for the serum chemerin levels with body weight, insulin levels, HOMA-IR, the levels of TC, TG, LDL and CRP, while a significant negative correlation was found between its levels and serum levels of HDL. Moreover chemerin was correlated negatively with the BT, WBCT, PT, aPTT and positively correlated with plasma fibrinogen, while there was insignificant correlation with platelet count. These results suggested that chemerin may represent a novel link between obesity and its haemostatic and atherogenic complication.
\end{abstract}

Keywords: Lipid Profile, HFD, PT, aPTT, Bleeding time, CRP, Chemerin.

\section{INTRODUCTION}

Obesity, the most common nutritional disorder, has reached epidemic proportions worldwide, particularly in the highly industrialized Western societies [1]. Obese individuals are at increased risk for hypertension, dyslipidemia, cardiovascular disease, and type 2 diabetes [2,3]. Insulin resistance is a major factor underlying the adverse metabolic consequences of obesity $[4,5]$. Moreover, overweight and obesity belong to the group of chronic diseases in which there is a substantially increased risk of haemostatic disorders, including excessive activation of coagulation system, inhibition of fibrinolysis, decreased endothelial thrombo-resistance and/or pro-inflammatory state $[6,7]$.

Adipose tissue represents an active endocrine organ that releases a large number of bioactive mediators (adipokines) which signal to organs of metabolic importance including brain, liver, skeletal muscle, and immune system, thereby modulating haemostasis, blood pressure, lipid and glucose metabolism, inflammation, and atherosclerosis [8].

Chemerin is a recently discovered adipokine that has been reported to modulate the immune system function

\footnotetext{
*Address correspondence to this author at the Department of Physiology, Faculty of Medicine, Zagazig University, Zagazig, Egypt;

Tel: 009663856972; Ext: 111; Fax: 009663856971 ;

E-mails: omarpubmed@yahoo.com/imrjan@qu.edu.sa
}

through its binding to the chemerin receptor (Chemerin R, a $\mathrm{G}$ protein-coupled receptor) [9]. Expression of chemerin and its receptor increases during the differentiation of preadipocytes into adipocytes. A critical function of chemerin/ ChemerinR is to regulate adipogenesis and metabolic homeostasis in adipocytes in mice and humans [10]. Recent results also indicate that chemerin and Chemerin receptor could have an important biological role in the formation of white adipose tissue during normal development and in pathological states such as obesity $[10,11]$.

Importantly, chemerin is widely expressed and circulates in human plasma as inactive pro-protein form and undergoes extracellular serine protease cleavage of the $\mathrm{C}$-terminal portion of the protein to generate the $16 \mathrm{kDa}$ active chemerin which is present in plasma and serum [12]. The clottingassociated serine proteases, factors XIIa and VIIa, and the fibrinolysis-associated serine proteases, plasmin and plasminogen activators can all activate chemerin. Inflammatory cell-associated serine proteases, including neutrophil granule elastase and mast cell tryptase, are activators as well [13]. These findings indicated that chemerin was activated through the haemostatic process while its effect on the haemostasis is not clear. However it's clearly obvious that chemerin represent the link between the inflammatory process and haemostatic process [13].

Chemerin serum concentrations are elevated in obese, insulin-resistant, and inflammatory states in vivo and 
suggested to be an obvious cause of insulin resistance [14, 15]. Obesity induces inflammation in adipose tissue and since chemerin is a pro-inflammatory cytokine that recruits and activates immune cells and contributes to inflammation by promoting macrophage adhesion to vascular cell adhesion molecule-1 (VCAM-1) and fibronectin, it may link obesity and vascular inflammation [16].

Serum chemerin levels were positively correlated with key metabolic syndrome (MS) markers such as elevated levels of body mass index (BMI), fasting plasma glucose (FPG), fasting serum insulin (FSI), homeostasis model assessment for insulin resistance (HOMA-IR), serum triglyceride (TG), low density lipoprotein (LDL) and blood pressure $[17,18]$. The indicater correlation between chemerin and atherogenic lipid profile supports the proposed relation between it and the increased incidence of thromboembolic complication reported with obesity.

Studies have suggested that elevated serum chemerin levels were strongly related to inflammatory markers such as high sensitivity CRP $[19,20]$. Moreover, recent studies have associated chemerin with several inflammatory markers in obesity and type-2 diabetes [20, 21]. Thus, chemerin is considered a candidate in linking inflammation to obesityrelated diseases.

As the increased risk of thrombo-embolic incidents represents one of the most important disorders associated with obesity, the current study was designed to clarify the possible relationship between chemerin levels and some haemostatic and atherogenic changes in obese rats.

\section{MATERIAL AND METHODS}

\subsection{Study Design}

- This study was conducted on 20 healthy, adult, male albino rats weighing $180 \pm 22$ gm (animals were obtained from the animal house of Veterinary Medicine college). The rats had free access to water and chow and are kept at room temperature.

- The animals were left 2 weeks for acclimatization and all the metabolic parameters were measured for animals before starting the experiment to be sure that all animals were starting from the same metabolic state. Then animals were divided into 2 main groups: Group I: (10 rats) they served as controls and received standard chow (25.8\% protein, $62.8 \%$ carbohydrate and $11.4 \%$ fat (total $12.6 \mathrm{~kJ} / \mathrm{g}$ ) [22].

- Group II: (10 rats) they received high fat chow, (16.4\% protein, $25.6 \%$ carbohydrate, and $58.0 \%$ fat (total $23.4 \mathrm{~kJ} / \mathrm{g}$ ) in the form of cotton seed oil added to the laboratory chow diet [23] for 8 weeks. Diets were obtained from Faculty of Agriculture, Zagazig University.

- For both groups, body weight was recorded at the start (initial), and at the end of the study period (final).

- At the end of the experiment ( $8^{\text {th }}$ week) after overnight fasting, at 8:00 am, the bleeding time was estimated for both groups then the blood sample collected from the sinus orbitus vein of each rat after ether inhalation [24]. The blood sample was divided into three vials. The first one was containing $3.2 \%$ sodium citrate in the ratio 1:9 with the blood sample. The blood was then centrifuged at $2000 \mathrm{rpm}$ for 15 min to obtain plasma. Plasma was used for measuring the PT, aPTT, platelet count and fibrinogen. While, Serum were obtained by allowing the blood samples to clot at room temperature before centrifuging. The samples were stored at $-20^{\circ} \mathrm{C}$ and used for estimation of the biochemical and hormonal parameters. However the third vial was filled with fresh whole blood and used for measuring the WBCT.

\subsection{Estimation of Haemostatic Parameters}

- Bleeding time (BT): The bleeding time was determined using a modified tail cutting method, as described by Dejana et al. [25]. The rats were placed in a plastic cylinder with several openings from one of which the animal's tail emerged out. The rats were maintained at room temperature. Bleeding times were measured by transaction of tail; $2 \mathrm{~mm}$ from the tip using disposable surgical blade. The cut was dabbed with filter paper every $15 \mathrm{sec}$. until the paper no longer stained red with blood. Bleeding time was then taken as the time when the blood stopped flowing from the cut tail.

- Whole blood clotting time (WBCT): according to Quick, [26]. Blood was taken directly from the sinus orbitus vein to avoid contamination with tissue thromboplastin $(0.8 \mathrm{ml}$ from each rat). A $0.2 \mathrm{ml}$ of blood was then delivered into four glass test tubes that had previously been warmed and maintained at $37^{\circ} \mathrm{C}$ and the tubes immediately placed in a $37^{\circ} \mathrm{C}$ water bath to mimic the temperature of the internal environment. The stopwatch was started immediately the blood was delivered into the glass test tubes and the tubes were continually tilted at $40 \mathrm{sec}$ intervals (until blood in them stopped flowing when tilted at an angle of $90^{\circ}$ ), starting with the first, to see and note the time when the blood clotted. The clotting time was taken as the average of the times blood clotted in the four tubes.

- Prothrombin time (PT) and Partial thromboplastin time (PTT) by automated blood coagulation analyzer (Sysmex -CA 1500, Japan) according to Cooper and Douglas method [27].

- Platelet count by automated analyzer (Sysmex-KX $21 \mathrm{~N}$ - Sysmex Corporation).

\subsection{Estimation of Biochemical and Hormonal Levels}

- Serum glucose levels according to Trinder [28] using glucose enzymatic (GOD-PAP)-liquizyme Kits (Biotechnology, Egypt).

- Serum insulin by a solid phase enzyme amplified sensitivity immunoassay according to Starr et al. [29] using KAP1251-INS-EASIA (Enzyme Amplified Sensitivity Immunoassay) Kits (BioSource Europe S.A., Belgium).

- Serum chemerin levels: by enzymelinked immunosorbentassay kits from Quantikine ELISA., (USA) Catalog Number MCHM00, the minimum detectable dose (MDD) of mouse Chemerin ranged 
Table 1. Body Weights and Metabolic Parameters of the Control and HFD-Received Groups

\begin{tabular}{|c|c|c|}
\hline Parameters & $\begin{array}{l}\text { Control Group } \\
\qquad(n=10)\end{array}$ & $\begin{array}{l}\text { HFD-Received Group } \\
\qquad(n=10)\end{array}$ \\
\hline Initial BW (gm) & $193.7 \pm 8.00$ & $187.52 \pm 8.98$ \\
\hline Final BW (gm) & $213 \pm 8.80$ & $234.4 \pm 11.22^{* * * \# \# \#}$ \\
\hline Blood Glucose (mg/dl) & $80.8 \pm 3.82$ & $260.2 \pm 11.67^{* * *}$ \\
\hline $\begin{array}{l}\text { Insulin } \\
(\mu \mathrm{IU} / \mathrm{ml})\end{array}$ & $18.3 \pm 0.38$ & $43.8 \pm 1.61^{* * *}$ \\
\hline HOMA-IR & $3.7 \pm 0.17$ & $28.1 \pm 1.78^{* * *}$ \\
\hline $\begin{array}{l}\text { Chemerin } \\
(\mathrm{Pgm} / \mathrm{ml})\end{array}$ & $4.9 \pm 0.35$ & $7.4 \pm 0.53^{* * *}$ \\
\hline $\mathrm{TC}(\mathrm{mg} / \mathrm{dl})$ & $114.7 \pm 0.87$ & $202.8 \pm 8.12^{* * *}$ \\
\hline $\mathrm{TG}(\mathrm{mg} / \mathrm{dl})$ & $48.3 \pm 1.63$ & $187.7 \pm 7.75^{* * *}$ \\
\hline HDL(mg/dl) & $59.5 \pm 2.15$ & $33.9 \pm 2.59^{* * *}$ \\
\hline $\mathrm{LDL}(\mathrm{mg} / \mathrm{dl})$ & $45.6 \pm 2.41$ & $131.4 \pm 4.52^{* * *}$ \\
\hline CRP (mg/l) & $2.9 \pm 0.26$ & $3.3 \pm 0.27^{* *}$ \\
\hline
\end{tabular}

$* * * \mathrm{p}<0.001$ when compared with control

$* * \mathrm{p}<0.01$ when compared with control

$\mathrm{p}>0.05$ when compared with control.

$\# \# \#$ p $<0.001$ when compared with initial BW.

from 1.08-3.47 $\mathrm{pg} / \mathrm{mL}$. The mean MDD was 1.88 $\mathrm{pg} / \mathrm{mL}$.

- Total Serum cholesterol (TC) levels: by Total Cholesterol (TC) TRTU 61218 kits for enzymatic determination of total cholesterol (bioMerieux S.A., Lyon, France) according to Allain et al. [30].

- Serum triglycerides (TG) levels by ESPAS SL kits: enzymatic determination of triglycerides (Elttech S.A., Sees, France) according to Naito, [31].

- Serum high density lipoproteins (HDL) levels by enzymatic colorimetric method according to Warnick et al. [32], using Stanbio HDL-cholesterol procedure No. 0599 kits (Stanbio laboratory Inc., San Antonio, Texas, USA).

- Low density lipoprotein cholesterol according to Friedewald et al. [33] LDL was calculated as follows: $\mathrm{LDL}=\mathrm{TC}-\mathrm{HDL}-\mathrm{TG} \backslash 5$.

- $\mathrm{C}$ - reactive protein (CRP): it was assayed by latex agglutination method [34].

\subsection{Estimation the Homeostasis Model of Assessment of} Insulin Resistance

- The HOMA-IR= fasting insulin $(\mu \mathrm{U} / \mathrm{ml}) \mathrm{x}$ fasting plasma glucose (mg/dl) / 405 [35].

All the biochemical and hormonal parameters were measured in the Department of Medical Biochemistry while the haemostatic parameters were measured in the Department of Clinical Pathology, Faculty of Medicine, Zagazig University, Egypt.
Table 2. The Haemostatic Parameters of the Control and HFDReceived Groups

\begin{tabular}{|c|c|c|}
\hline Parameters & $\begin{array}{c}\text { Control Group } \\
(\mathbf{n = 1 0})\end{array}$ & $\begin{array}{c}\text { HFD-Received group } \\
(\mathbf{n}=\mathbf{1 0})\end{array}$ \\
\hline \hline BT (sec) & $209.8 \pm 1.32$ & $181.0 \pm 5.64^{* * *}$ \\
\hline WBCT (sec.) & $225.4 \pm 2.17$ & $174.1 \pm 3.17^{* * *}$ \\
\hline PT (Sec) & $12.48 \pm 0.74$ & $10.2 \pm 0.45^{* * *}$ \\
\hline aPTT (sec) & $24.5 \pm 0.85$ & $14.7 \pm 0.51^{* * *}$ \\
\hline Fibrinogen (mg/dl) & $283.6 \pm 2.10$ & $300.4 \pm 11.59^{* *}$ \\
\hline Platelet count & $210.5 \pm 1.86$ & $210.68 \pm 1.87^{\S}$ \\
$(1000 / \mathrm{mm} 3)$ & & \\
\hline
\end{tabular}

$* * * \mathrm{p}<0.001$ when compared with control

$* * \mathrm{p}<0.01$ when compared with control

$\$ p>0.05$ when compared with control.

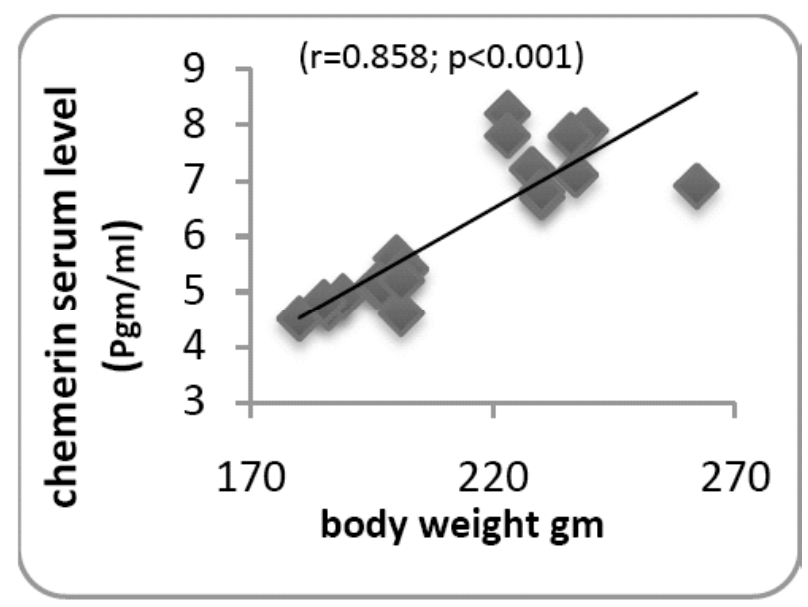

Fig. (1). The correlation between chemerin serum levels and body weights.

\subsection{Statistical Analysis}

The data obtained in the present study were expressed as mean \pm SD for quantitative variables and statistically analyzed by using SPSS program (version 17 for windows) (SPSS Inc. Chicago, IL, USA). The differences between mean values for each element were tested by student's " $t$ " test. $\mathrm{P}<0.05$ was considered significant. Correlations were performed by Pearson 2 tailed test.

\section{RESULTS}

The metabolic, hormonal and the haemostatic parameters of the groups are summarized in Table $\mathbf{1}$ and $\mathbf{2}$, respectively.

The HFD-fed rats (GII) showed a significant increase $(\mathrm{p}<0.001$ for all and $\mathrm{P}<0.01$ for $\mathrm{CRP}$ ) in body weights, serum levels of glucose, insulin, chemerin, HOMA-IR, TC, TG, LDL and CRP when compared with the control group (GI), while there was a significant decrease $(p<0.001)$ in HDL levels in comparison with that of controls (GI). In addition, a significant positive correlation was detected for the chemerin serum levels with body weight $(\mathrm{r}=0.858$; $\mathrm{p}<0.001)$ Fig. (1), insulin levels $(\mathrm{r}=0.931 ; \mathrm{P}<0.001)$, HOMAIR $(\mathrm{r}=0.941 ; \mathrm{P}<0.001)$ Fig. (2), levels of $\mathrm{TC}(\mathrm{r}=0.943$; $\mathrm{p}<0.001)$, TG $(\mathrm{r}=0.945 ; \mathrm{p}<0.001)$, LDL $(\mathrm{r}=0.951 ; \mathrm{p}<0.001)$ 


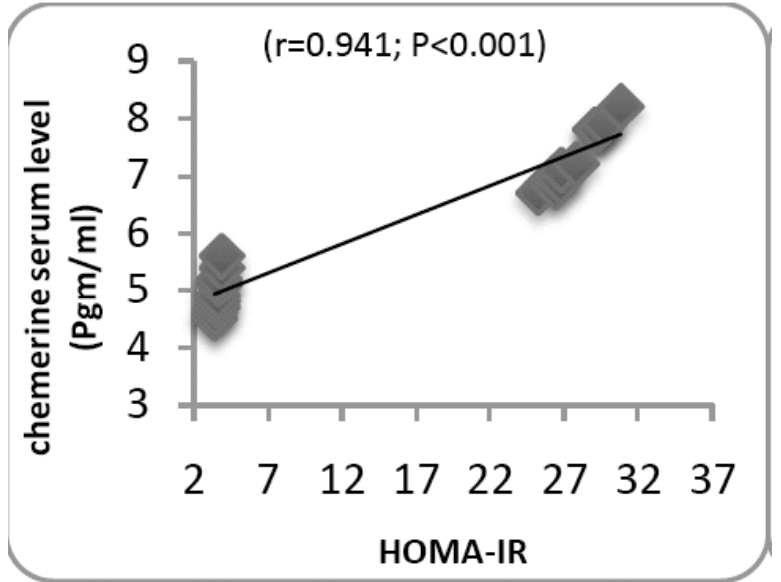

Fig. (2). The correlation between chemerin Serum level and HOMA-IR.

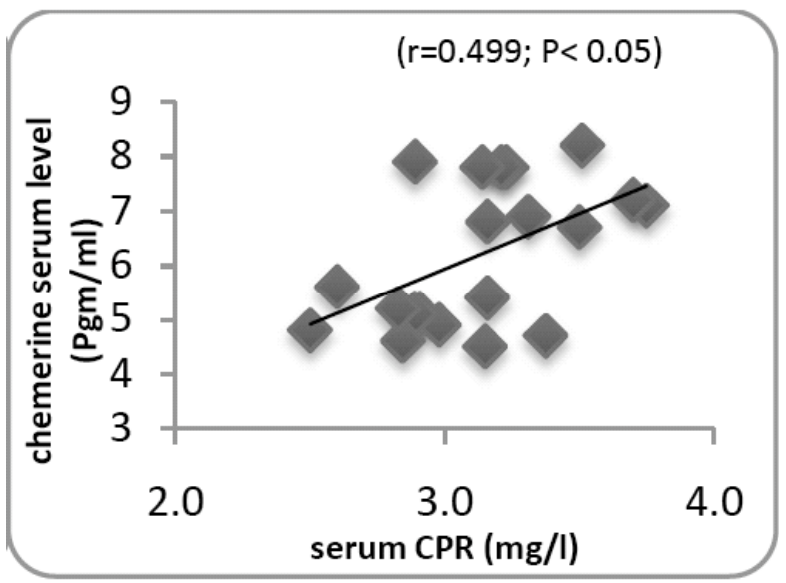

Fig. (3). The correlation between chemerin and CRP serum levels.

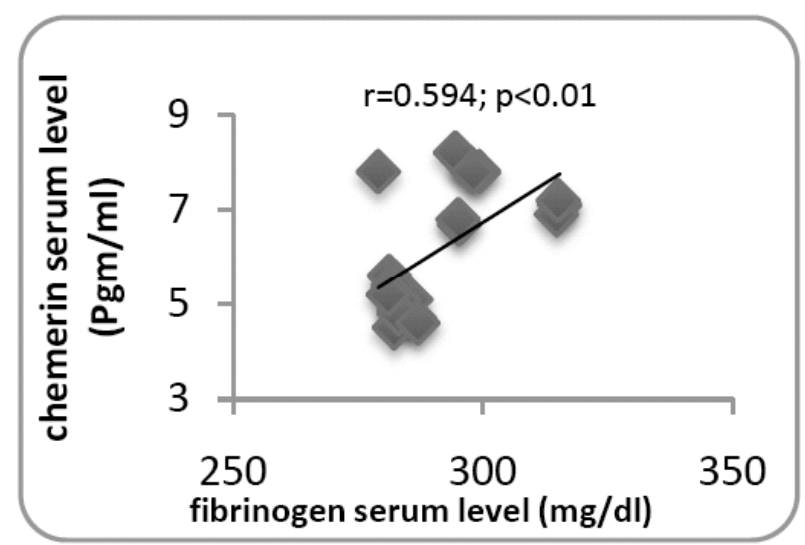

Fig. (4). The correlation between chemerin and fibrinogen serum levels.

and CRP $(\mathrm{r}=0.499 ; \mathrm{P}<0.05)$ Fig. (3), while a significant negative correlation was found between its levels and serum levels of HDL $(r=0.915 ; \mathrm{p}<0.05)$.

The BT, WBCT, PT and aPTT were found to be significantly decreased $(\mathrm{p}<0.001$ for all $)$, while, plasma fibrinogen levels were found to be significantly increased $(\mathrm{p}<0.01)$. There was insignificant change in the platelets count $(\mathrm{P}>0.05)$.

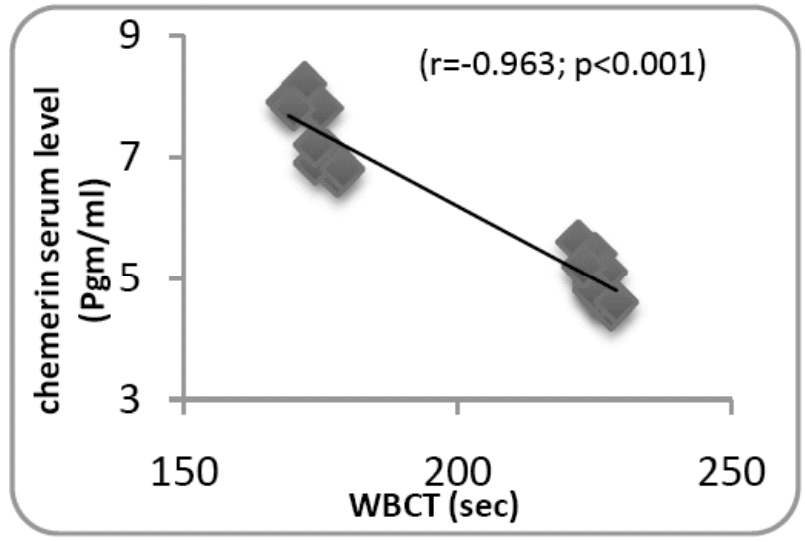

Fig. (5). The correlation between chemerin Serum level and WBCT.

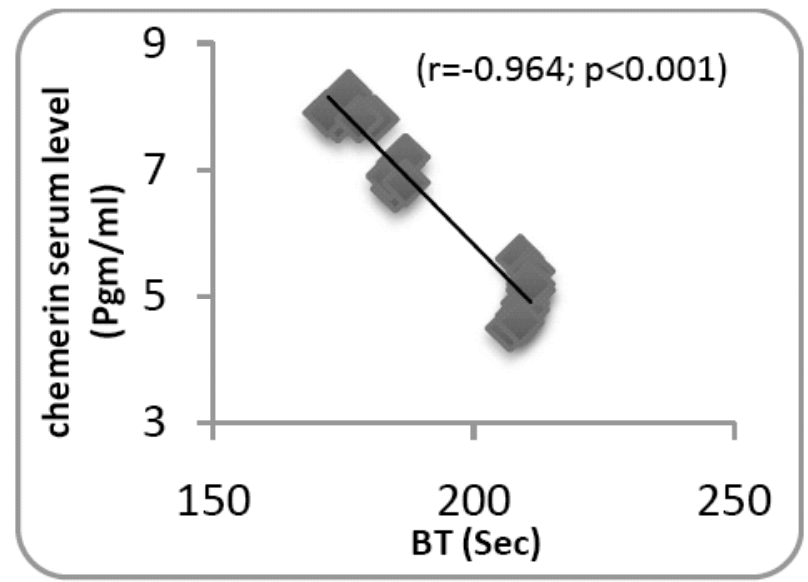

Fig. (6). The correlation between chemerin serum levels and BT.

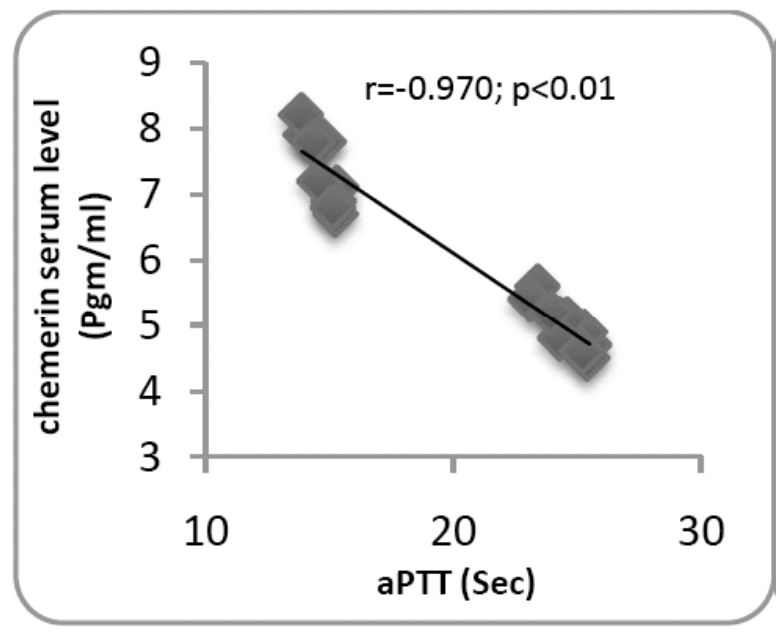

Fig. (7). The correlation between chemerin serum levels and aPTT.

Chemerin levels were found to be correlated negatively and significantly with BT $(r=-0.964 ; p<0.001)$ Fig. (4), WBCT $(\mathrm{r}=-0.963 ; \mathrm{p}<0.001)$ Fig. (5), PT $(\mathrm{r}=-0.948 ; \mathrm{p}<0.05)$ Fig. $(6)$, aPTT $(r=-0.970 ; p<0.01)$ Fig. $(7)$ and positively correlated with plasma fibrinogen $(\mathrm{r}=0.594 ; \mathrm{p}<0.01)$ Fig. (8), while there was insignificant correlation with platelet count $(r=0.193 ; p>0.05)$ Fig. (9). 


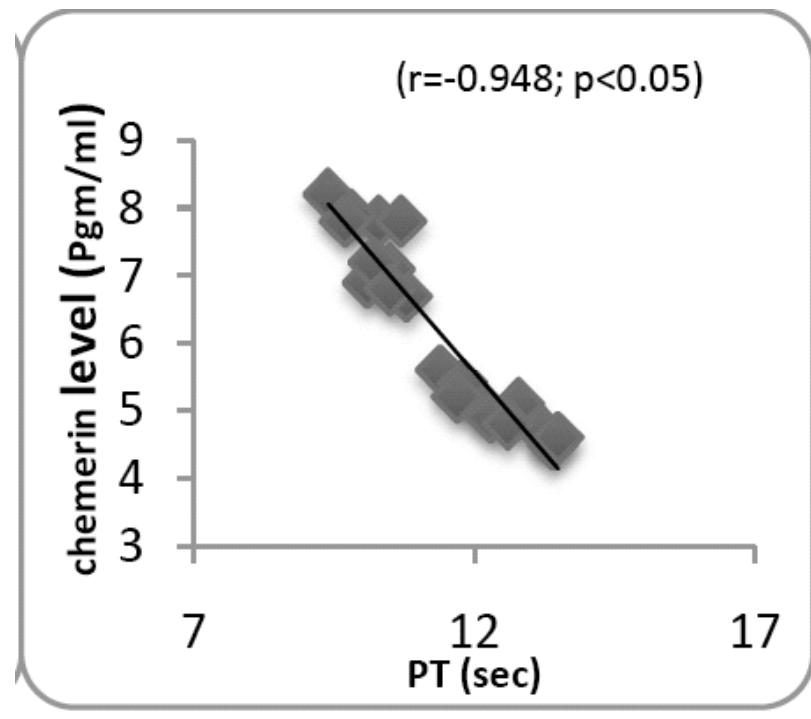

Fig. (8). The correlation between chemerin Serum level and PT

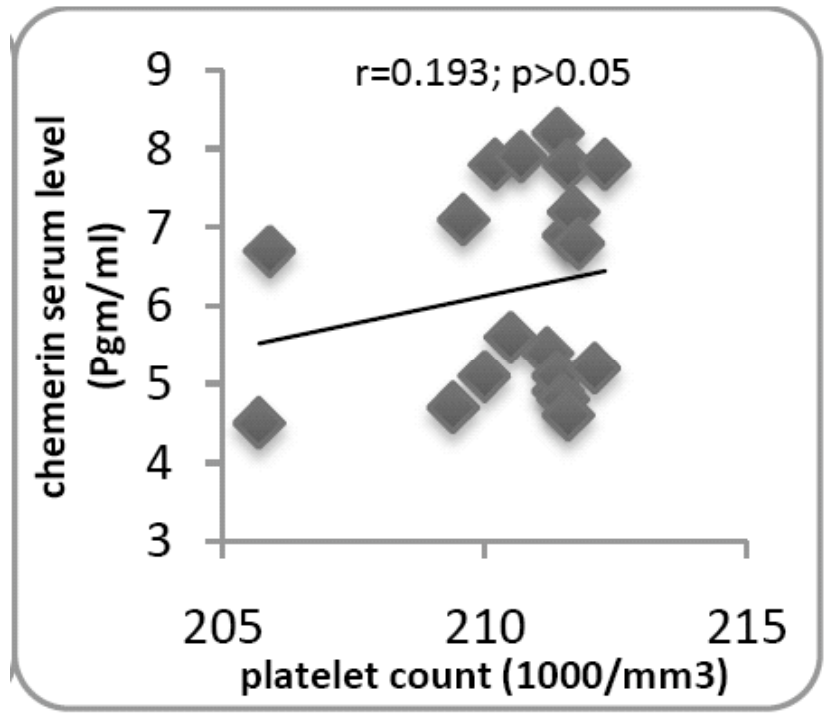

Fig. (9). The correlation between chemerin and platelet counts.

\section{DISCUSSION}

The unfavorable levels of fitness and adiposity were associated with higher levels of hemostatic markers, putting individuals with this profile at greater risk for future cardiovascular disease [36].

Recent findings strongly suggest that white adipose tissue serves as both a primary source of chemerin secretion as well as a target for autocrine/paracrine chemerin signaling [9, 12]. Yan et al. [37] indicated that higher serum chemerin levels were associated with increased risk of coronary artery disease (CAD) and metabolic parameters in Chinese. This finding suggested that chemerin may represent a novel link between metabolic signals and atherosclerosis.

The results of the present study revealed increase in the levels of, chemerin, glucose, insulin, HOMA-IR, TC, TG, and LDL in the HFD-fed rats and significant decrease in the level of HDL in comparison to the control group. Moreover, there were significant positive correlations between chemerin serum levels and the levels of insulin, HOMA-IR, TC, TG, and LDL and negative correlation between its levels and the HDL. These results are concurrent with the results of Yan et al. [37] and Landgraf et al. [38]. Moreover Chakaroun et al. [39] indicated that all interventions led to significant reduction in the body weight; weeks exercise, 6 months of calorie-restricted diet, and 12 months after bariatric surgery led to reduced chemerin serum concentrations that significantly correlate with improved glucose infusion rate, insulin sensitivity and subclinical inflammation and reduced C-reactive protein levels.

The positive correlation that indicated between chemerin levels and the atherogenic lipid profile and insulin resistance in the current study supports our proposed relation between it and the increased incidence of thrombo-embolic complication reported with obesity. However the causes of increased incidence of thrombo-embolic complication in obese may extend to involve, increased blood coagulation, decreased endothelial thrombo-resistance and/or proinflammatory state $[6,7]$.

The results of the current study revealed increase in the blood coagulation properties in the HFD-fed rats when compared with the control as there was a significant decrease in the BT, WBCT, PT and aPTT, and significant increase in the fibrinogen levels. Moreover we indicated significant negative correlation between the chemerin level and the BT, WBCT, PT and aPTT and significant positive correlation between its levels and fibrinogen levels. While there was insignificant positive correlation indicated between it and the platelet count.

To the best of our knowledge, the effect of chemerin on the coagulation properties was not investigated before. However several studies have reported a positive association between the measures of obesity, specifically body mass index and plasma fibrinogen in both adult [40] and children $[41,42]$. Another study indicated increases in the activities of fibrinogen and clotting factors IX, XI, XII, and plasminogen activator inhibitor-1 (PAI-1) in obese and considered this simultaneous activities of intrinsic coagulation factors and impaired fibrinolysis as predisposing factor for thrombosis [43].

As regard the platelet count, the results revealed insignificant difference in platelet count between HFD-fed group and control group. This result was against the findings of Foschini et al. [44] who indicated that Obese adolescents have higher platelet and leptin concentrations in comparison with non-obese adolescents and the results of Coban et al. [45] who found a positively correlation between the mean platelet volume (MPV), a determinant of platelet function with BMI in obese group. These contradictory findings could be attributed to genetic factors and species difference.

Evidences have cumulated to show that C-reactive protein levels are associated with different aspects of the cardiovascular risk spectrum. For instance, C-reactive protein levels were higher among people who were physically inactive, [46, 47] and were more obese [48]. Creactive protein levels were also associated with the presence and extent of the metabolic syndrome [48, 49], with the presence of subclinical atherosclerosis [50], and with the progression of atherosclerosis [51].

In the HFD fed rats a significant correlation was found between chemerin levels and inflammation as depicted by 
significantly raised levels of highly sensitive CRP, the marker of inflammation. This result was in line with the results of Landgraf et al. [38] who indicated a significant associations of chemerin with the measures of inflammation high-sensitivity C-reactive protein and white blood cell count, as well as with the markers of endothelial activation intercellular adhesion molecule-1 (ICAM-1) and E-selectin. Thus chemerin has been associated with obesity, inflammatory and endothelial activation markers supporting its role as a molecular link between increasing fat mass and an early atherogenic risk profile in obese children [38].

Further study that investigated the role of chemerin as a novel link between metabolic signals and atherosclerosis has been revealed that Serum chemerin levels were significantly higher in the coronary artery disease (CAD) group than in the non-CAD group [37]. Moreover the Serum chemerin levels were significantly increased with the increasing number of diseased vessels.

\section{CONCLUSION}

The results of the current study revealed that chemerin level increased in the HFD- fed rats and significantly correlated with the BW, HOMA-IR, and the atherogenic lipid profile. While, it was correlated negatively with the BT, WBCT, PT and aPTT, also a positive correlation between the chemerin levels and fibrinogen and CRP has been detected. These results suggest that chemerin may represent a novel link between obesity and its associated cardiovascular complications.

\section{FUNDING}

This research received no specific grant from any funding agency in the public commercial or not-for-profit sectors.

\section{CONFLICT OF INTEREST}

The authors confirm that this article content has no conflicts of interest.

\section{ACKNOWLEDGEMENTS}

The author is grateful to faculty of Medicine- Zagazig University for providing the necessary facilities and also would like to acknowledge all the contributors in the Departments of Clinical Pathology and Medical Biochemistry for providing greet help in the analytic part of the research.

\section{ABBRIVIATIONS}

$\begin{array}{ll}\text { HFD } & =\text { High fat diet } \\ \mathrm{TC} & =\text { Total Cholesterol } \\ \mathrm{TG} & =\text { Triglycerides } \\ \mathrm{HDL} & =\text { High Density Lipoprotein Cholesterol } \\ \mathrm{LDL} & =\text { Low Density Lipoprotein Cholesterol } \\ \mathrm{BT} & =\text { Bleeding Time } \\ \mathrm{WBCT} & =\text { Whole Blood Clotting Time } \\ \mathrm{PT} & =\text { Prothrombin time } \\ \text { aPTT } & =\text { Activated Partial Thromboplastin Time }\end{array}$

$\begin{array}{lll}\text { CRP } & =\text { C- Reactive Protein } \\ \text { MS } & =\text { Metabolic Syndrome } \\ \text { BMI } & =\text { Body mass index } \\ \text { VCAM-1 } & \text { Vascular cell adhesion molecule-1 } \\ \text { FPG } & =\text { Fasting Plasma Glucose } \\ \text { CAD } & =\text { Coronary Artery Disease } \\ \text { HOMA-IR } & =\begin{array}{l}\text { Homeostasis Model Assessment for } \\ \text { Insulin Resistance }\end{array}\end{array}$

\section{REFERENCES}

[1] Hossain P, Kawar B, El Nahas M. Obesity and diabetes in the developing world: a growing challenge. N Engl J Med 2007; 356: 213-5.

[2] Muoio DM, Newgard CB. Obesity-related derangements in metabolic regulation. Annu Rev Biochem 2006; 75: 367-401

[3] Poirier P, Giles TD, Bray GA, et al. Obesity and cardiovascular disease, pathophysiology evaluation and effect of weight loss. Arterioscler Thromb Vasc Biol 2006; 26: 968-76.

[4] Reaven GM. The insulin resistance syndrome. Curr Atheroscler Rep 2003; 5: 364-71

[5] Wilcox G. Insulin and insulin resistance. Clin Biochem Rev 2005; 26: 19-39.

[6] Swiatkowska-Stodulska R, Kazimierska E, Sworczak K, Czestochowska E. Hemostatic disturbances in obesity. Wiad Lek 2007; 60 (3-4):185-8.

[7] Palomo I, Alarcon M, Moore-Carrasco R, Argiles JM. Hemostasis alterations in metabolic syndrome. Int J Mol Med 2006; 18: 96974.

[8] Rabe K, lehrke M, parhofer KG, Broedl U. Adipokines and insulin resistance. Mol Med 2008; 14:741-51.

[9] Bozaoglu K, Bolton K, McMillan J, et al. Chemerin is a novel adipokine associated with obesity and metabolic syndrome. Endocrinology 2007;148 (10): 4687-94.

[10] McKeehan WL, Wang F, Kan M. The heparan sulfate-fibroblast growth factor family. Prog Nucleic Acid Res Mol Biol 1998; 59:135- 76 .

[11] Ornitz NI. Fibroblast growth factors. Genome Biol 2001; 2(3), reviews 3005.1-3005.12.

[12] Stejskal D, Karpisek M, Hanulova Z, Svestak M. Chemerin is an independent marker of the metabolic syndrome in a Caucasian population-a pilot study. Biomed Pap Med Fac Univ Palacky Olomouc Czech Repub 2008; 152: 217-21.

[13] Zabel BA, Allen SJ, Kulig P, et al. Chemerin Activation by Serine Proteases of the Coagulation, Fibrinolytic, and Inflammatory Cascades. J Biol Chem 2005; 280(41): 34661-6.

[14] Hart R, Greaves DR. Chemerin Contributes to Inflammation by Promoting Macrophage Adhesion to VCAM-1 and Fibronectin through Clustering of VLA-4 and VLA-5. J Immunol 2010;185 (6): 3728-39.

[15] Lambernd S, Taube A, Schober A, et al. Contractile activity of human skeletal muscle cells prevents insulin resistance by inhibiting pro-inflammatory signalling pathways. Diabetologia 2012; 55 (4):1128-39.

[16] Ouchi N, Parker JL, Lugus JJ, Walsh K. Adipokines in inflammation and metabolic disease. Nat Immunol 2011;11(2): 8597.

[17] McCarthy TC, Zuniga LA, Zabel BA, Butcher EC, Sinal CJ. The novel adipokine chemerin significantly increases cholesterol uptake in human macrophages. FASEB J 2008; 22: 948-8.

[18] McGowan MW, Artiss JD, Strodbrgh DR. A peroxidase-coupled method for the colorimetric determination of serum triglycerides. Clin Chem.1983; 29: 273-8.

[19] Lehrke M, Becker A, Greif M, et al. Chemerin is associated with markers of inflammation and components of the metabolic syndrome but does not predict coronary atherosclerosis. Eur J Endocrinol 2009; 161: 339-44.

[20] Weigert J, Neumeier M, Wanninger J, et al. ystemic chemerin is related to inflammation rather than obesity in type 2 diabetes. Clin Endocrinol (Oxf). 2010; S 72:342-8. 
[21] Ress C, Tschoner A, Engl J, et al. Effect of bariatric surgery on circulating chemerin levels. Eur J Clin Invest 2010;40:277-80.

[22] Ahren B, Scheurink AJW. Marked hyperleptinemia after high fat diet associated with severe glucose intolerance in mice. Eur $\mathrm{J}$ Endocrinol 1998; 139:461-7.

[23] Cha MC, Chou J, Boozer CN. High-fat diet feeding reduces the diurinal variation of plasma leptin concentration in rats. Metabolism 2000; 48:503-7.

[24] Yang H, Lauv S, Sinclair DA. Nampt/ PBEF/ Visfatin: a regulator of mammalian health and longevity. Exp Geront 2006; 41:718-26.

[25] Dejana E, Villa S, de Gartano G. Bleeding time in rats: a comparison of different experimental conditions. Thromb Haemostasis 1982;48:108-11.

[26] Quick AJ, Eds. Hemorrhage disease and thrombosis. $9^{\text {th }}$ ed. Philadelphia: Lea and Febiger, 1966; p. 209.

[27] Cooper J, Douglas A. Fibrinogen level as a Predictor of mortality in survivers of myocardial infarction. Fibrinolysis 1991; 5:105-8.

[28] Trinder P. Enzymatic determination of glucose. Ann Clin Biochem $1969 ; 6: 24-7$.

[29] Starr JI, Mako ME, Juhn D, Rubenstein AH. Measurement of serum pro-insulin-like material: cross reactivity of porcine and human proinsulin. J Lab Clin Med1978; 91:691-2.

[30] Allain C, Poon LS, Chan CS, Richmond W, Fu PC. Enzymatic determination of total serum cholesterol. Clin Chem 1974;20:4705 .

[31] Naito HK, Ed. Triglycerides In: Kaplan LA, Pesce AJ Eds. Clinical chemistry: theory, analysis and correlation. $2^{\text {nd }}$ ed. ST Louis: Mosby 1989; p. 997.

[32] Warnick GR, Benderson V, Albers N. Selected methods. Clin Chem 1983; 10:91-9.

[33] Friedwald WT, Levy RI, Fredrickson DS. Estimation of the concentration of low density lipoprotein cholesterol in plasma, without use of the preparative ultracentrifuge. Clin Chem 1972; 18:499-502.

[34] Singer JM, Piotz CM, Parker E, Elster SF. The latex-fixation test. III. Agglutination test for Creactive proteins and comparison with the capillary precipitin method. Am J Clin Pathol 1975;28: 611- 7.

[35] Matthews DR, Hosker JP, Rudenski AS, Naylor BA, Treacher DF, Turner RC. Homeostasis model assessment: insulin resistance and beta-cell function from fasting serum glucose and insulin concentrations in man. Diabetologia 1985;28:412-9.

[36] Barbeau P, Litaker MS, Woods KF, et al. Hemostatic and inflammatory markers in obese youths: effects of exercise and adiposity. J Pediatr 2002;141(3):415-20.

[37] Yan Q, Zhang Y, Hong J, et al. The association of serum chemerin level with risk of coronary artery disease in Chinese adults. Endocrine 2012;41 (2):281-8.
[38] Landgraf K, Friebe D, Ullrich T, et al. Chemerin as a Mediator between Obesity and Vascular Inflammation in Children. J Clin Endocrinol Metab 2012; 97 (4): E556-64.

[39] Chakaroun R, Raschpichler M, Klöting N, et al. Effects of weight loss and exercise on chemerin serum concentrations and adipose tissue expression in human obesity. Metabolism 2012; 61(5):70614.

[40] Woodward M, Lowe G, Rumley A, Tunstallpedoe H, Philippou H, Lane D. Epidemiology of coagulation factors, inhibitors and activation markers: the third Glasgow MONICA survey. II Relationships to cardiovascular risk factors and prevalent cardiovascular disease. Br J Haematol 1997; 97:785-97.

[41] Zahavi I, Yaari S, Salman H, et al. Plasma fibrinogen in Israeli Moslem and Jewish school-children: distribution and relation to other cardiovascular risk factors. Isr J Med Sci. 1996; 32:1207-12.

[42] Ferguson MA, Gutin B, Owens S, et al. Fat distribution and hemostatic measures in obese children. Am J Clin Nutr. 1998; 67:1136-40.

[43] Kaye SM, Pietiläinen KH, Kotronen A, et al. Obesity-related derangements of coagulation and fibrinolysis: a study of obesitydiscordant monozygotic twin pairs. Obesity 2012; 20(1): 88-94.

[44] Foschini D, Ronaldo VT dos Santos, Wagner L Prado, et al. Platelet and leptin in obese adolescents. J. Pediatr 2008; 84(6): 51621.

[45] Coban E, Ozdogan M, Yazicioglu G, Akcit F. The mean platelet volume in patients with obesity. Int J Clin Pract 2005; 59(8):981-2.

[46] Ford ES. Does exercise reduce inflammation? Physical activity and C-reactive protein among U.S. adults. Epidemiology 2002;13:5618.

[47] Wannamethee SG, Lowe GD, Whincup PH, Rumley A, Walker M, Lennon L. Physical activity and hemostatic and inflammatory variables in elderly men. Circulation 2002; 105:1785-90.

[48] Rutter MK, Meigs JB, Sullivan LM, D’Agostino RB, Wilson PW. C-reactive protein, the metabolic syndrome, and prediction of cardiovascular events in the Framingham Offspring Study. Circulation 2004; 110:380-5.

[49] Timpson NJ, Lawlor DA, Harbord RM, et al. C-reactive protein and its role in metabolic syndrome: Mendelian randomisation study. Lancet 2005; 366:1954-9.

[50] Khera A, De Lemos JA, Peshock RM, et al. Relationship between C-reactive protein and subclinical atherosclerosis: the Dallas Heart Study. Circulation 2006; 113:38-43.

[51] Tzoulaki I, Murray GD, Lee AJ, Rumley A, Lowe GD, Fowkes FG. C-reactive protein, interleukin-6, and soluble adhesion molecules as predictors of progressive peripheral atherosclerosis in the general population: Edinburgh Artery Study. Circulation 2005; 112:976-83.

Received: April 25, 2013

Revised: June 10, 2013

Accepted: June 18, 2013

(C) Morgan and Edrees; Licensee Bentham Open.

This is an open access article licensed under the terms of the Creative Commons Attribution Non-Commercial License (http://creativecommons.org/licenses/by-nc/3.0/) which permits unrestricted, non-commercial use, distribution and reproduction in any medium, provided the work is properly cited. 